\title{
Folded Coplanar Waveguide Slot Antenna on Silicon Substrates With a Polyimide Interface Layer
}

\author{
Andrew Bacon ${ }^{1}$, George E. Ponchak ${ }^{2}$, John Papapolymerou ${ }^{1}$, Nathan Bushyager ${ }^{1}$, and Manos \\ Tentzeris ${ }^{1}$. \\ 1. School of ECE, Georgia Institute of Technology, Atlanta, GA 30332-0250 \\ 2. NASA Glenn Research Center, Cleveland, $\mathrm{OH}$
}

Abstract- A novel mm-wave Coplanar Waveguide (CPW) folded slot antenna is characterized on low-resistivity Si substrate $(1 \Omega-\mathrm{cm})$ and a high resistivity $\mathrm{Si}$ substrate with a polyimide interface layer for the first time. The antenna resonates around $30 \mathrm{GHz}$ with a return loss greater than $14.6 \mathrm{~dB}$. Measured radiation patterns indicate the existence of a main lobe, but the radiation pattern is affected by a strong surface wave mode, which is greater in the high resistivity Si wafer.

\section{INTRODUCTION}

The possibility of low cost RF and microwave circuits integrated with digital and analog circuits on the same chip is creating a strong interest in silicon as a microwave substrate. Their operation on CMOS grade $\mathrm{Si}$, however, is degraded by high loss of transmission lines and antennas. To overcome this problem researchers have used two different approaches. In the first approach, high resistivity Si (HRS) wafers are used $(\rho>2500 \Omega-\mathrm{cm})$ [1]-[2] and traditional microwave components have a performance similar to those on dielectric substrates, such as GaAs. In the second approach, polyimide layers are used on top of the CMOS substrate to create an interface layer that can host low loss microwave components. Both microstrip and coplanar waveguide transmission lines fabricated in this way have exhibited low attenuation for an optimum polyimide thickness [3]-[4].

This paper presents the characterization of Coplanar Waveguide (CPW) folded slot antennas with a resonant frequency around $30 \mathrm{GHz}$ on a CMOS silicon substrate and an HRS wafer with a polyimide interface for the first time. Results from experimental measurements and 3-D Finite Element Method (FEM) analysis are presented.

\section{ANTENNA DESIGN AND FABRICATION}

The folded-slot antenna is a broad bandwidth planar antenna with maximum radiation at the broadside that is used in a variety of applications [5]. It consists of a folded-slot with a circumference approximately equal to one guided wavelength $\left(\lambda_{\mathrm{g}}\right)$ and can be fed with a CPW or Finite Ground Coplanar (FGC) waveguide from one end. A schematic of a folded-slot antenna with various parameters is shown in Fig. 1 . The actual CPW fed antenna had a finite width ground plane, but it was electrically large and thus not a true FGC folded slot antenna.

In order to operate such an antenna on a low resistivity $(1-20 \Omega-\mathrm{cm}) \mathrm{Si}$ wafer, the electric fields in the CPW must have minimum interaction with the lossy substrate. For this reason a thick layer $(20$ $\mu \mathrm{m}$ ) of polyimide (DuPont WE 1111) is deposited and cured on top of the wafer. The transmission line feeding the antenna was also designed for minimum coupling with the substrate according to [6]. A schematic of the proposed CPW structure can be seen in Fig. 2. Original simulations with Ansoft's HFSS, which is based on the Finite Element Method (FEM), were performed to determine the antenna impedance at resonance. These simulations revealed a relatively high value of resistance at resonance $(\mathrm{R} \sim 250 \Omega)$ and, therefore, a quarter-wave transformer was designed for optimum matching between the feeding line $\left(\mathrm{Zo}_{0}=60 \Omega\right)$ and the antenna. The transformer length was $1.075 \mathrm{~mm}$ while its impedance was approximately $124 \Omega(\mathrm{s}=10 \mu \mathrm{m}, \mathrm{w}=20 \mu \mathrm{m})$. The antenna resonance was fine-tuned further by inserting a $2.07 \mathrm{~mm}$ section of $60 \Omega$ line between the 
transformer and the folded slot. Table I summarizes the various antenna parameters. For the fabrication of the folded slot antenna, standard lithographic techniques were used, and the conductors were Au electroplated to a thickness of $3 \mu \mathrm{m}$. The same antenna design was fabricated on an HRS wafer using the same processing steps.

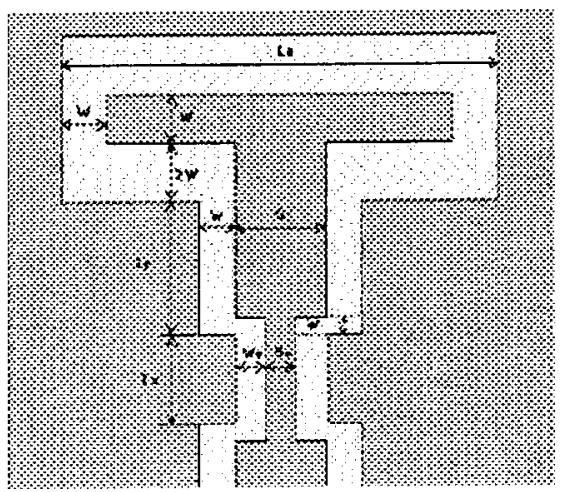

Figure 1: Geometry of folded slot antenna.

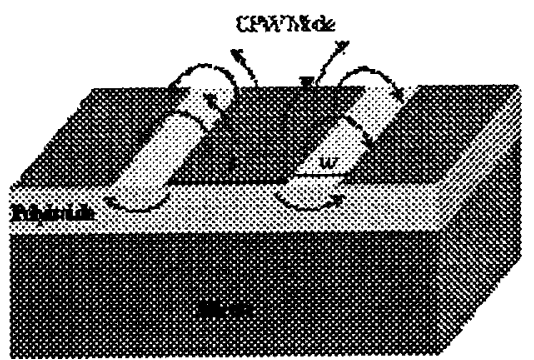

Figure 2: CPW line on Si substrate with a polyimide interface layer.

Table I. Design parameters for the folded-slot antenna

\begin{tabular}{|c|c|c|c|c|c|c|c|}
\hline Parameter & $\mathrm{La}$ & $\mathrm{L}_{\mathrm{F}}$ & $\mathrm{L}_{\mathrm{T}}$ & $\mathrm{W}_{\mathrm{T}}$ & $\mathrm{S}_{\mathrm{T}}$ & $\mathrm{S}$ & $\mathrm{W}$ \\
\hline Size $(\mu \mathrm{m})$ & 1024 & 2070 & 1075 & 20 & 10 & 50 & 10 \\
\hline
\end{tabular}

\section{RESULTS}

Simulated results with Ansoft's HFSS for the return loss of the matched antenna on CMOS Si can be seen in Fig. 3, where a value of $16.5 \mathrm{~dB}$ is predicted at $30 \mathrm{GHz}$. The substrate was assumed to be $500 \mu \mathrm{m}$ thick low resistivity silicon $(\sigma=100 \mathrm{~S} / \mathrm{m}, \tan \delta=0.0018)$ with a $20 \mu \mathrm{m}$ polyimide overlay of $\varepsilon_{\mathrm{T}}=2.8$. The top and side-walls of the box surrounding the antenna were radiation boundaries. $A$ perfect electric conductor was placed at the bottom of the Si substrate. Simulated E-plane radiation patterns at resonance are shown in Fig. 4, where a main lobe at broadside can be observed. For comparison purposes, the folded slot antenna was also simulated for high resistivity silicon using a parallel FDTD code developed by the ATHENA Research Group at Georgia Tech. The results indicated that under lossless conditions the antenna resonates near $27 \mathrm{GHz}$, with return losses of $25.6 \mathrm{~dB}$ at $27 \mathrm{GHz}$ and $2.65 \mathrm{~dB}$ at $30 \mathrm{GHz}$. EMAG Technologies, Inc. emPiCASSO ${ }^{\mathrm{Tw}}$ indicated a resonant frequency at $27 \mathrm{GHz}$ for the same geometry. A comparison of the data generated by the ATHENA FDTD code and emPiCASSO ${ }^{\text {th }}$ is shown in Fig. 5. However, with the incorporation of loss, the resonant frequency is increased to $30 \mathrm{GHz}$. The radiation patterns for the folded slot antenna were simulated with the ATHENA FDTD code, incorporating the matching network and emPiCASSO ${ }^{\text {ma }}$, which did not include the matching network. From Fig. 6, it can be seen that a smaller lobe of radiation is emanating from the lower portion of the antenna. This is where the matching network is located for the folded slot antenna. The emPiCASSO ${ }^{\text {ru }}$ simulations do not have this secondary radiation lobe.

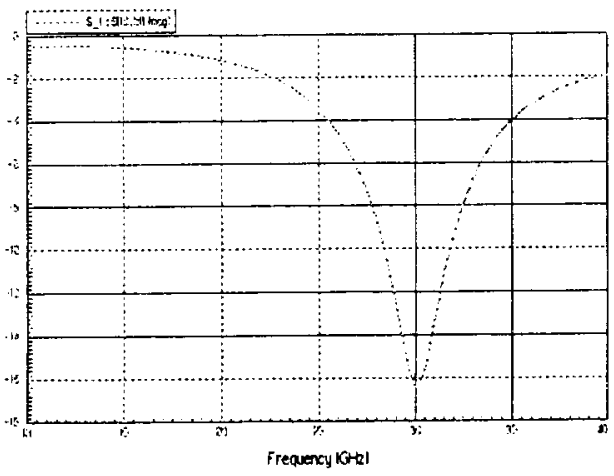

Figure 3: Simulated return loss of folded slot antenna on CMOS Si wafer with polyimide interface laver.

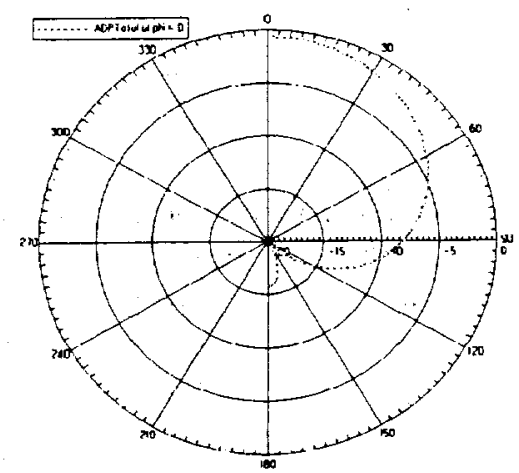

Figure 4: Simulated E-plane pattern with HFSS of a folded slot antenna on CMOS Si wafer. 


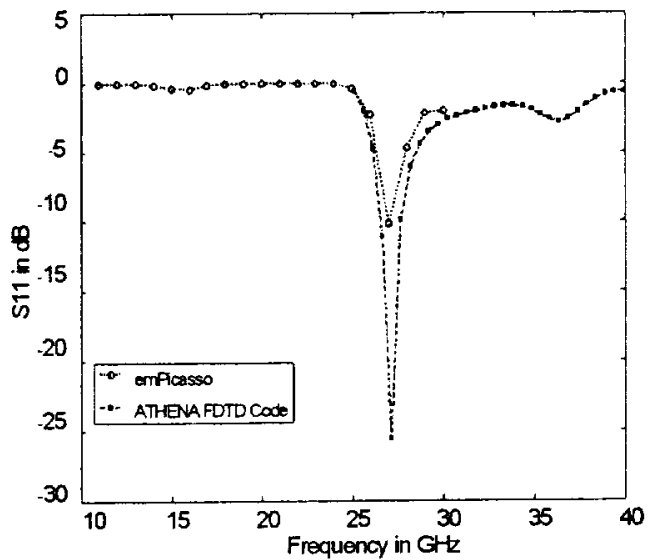

Figure 5: Simulated Return Loss of the Folded Slot Antenna Using emPicasso" and GA Tech's ATHENA FDTD Code.

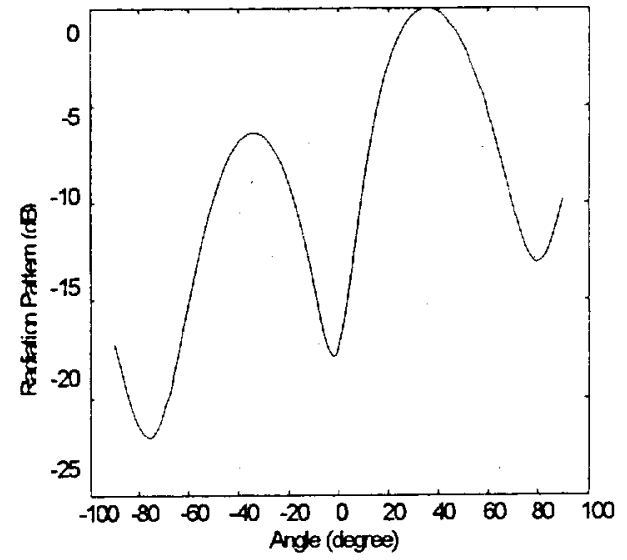

Figure 6: Simulated E-Plane Using GA Tech's ATHENA FDTD Code with Phi $=0$.

The antenna was characterized experimentally using an HP8510 Vector Network Analyzer and GGB Industries coplanar probes. The probe-to-FGC transition was de-embedded with a TRL calibration using Multical [7], that set the reference plane $500 \mu \mathrm{m}$ away from the transition. The effective dielectric constant and attenuation of the $60 \Omega$ lines on both substrates were measured and the results can be seen in Fig. 7. The measured attenuation is $5.7 \mathrm{~dB} / \mathrm{cm}$ for the FGC line on CMOS Si and $2.3 \mathrm{~dB} / \mathrm{cm}$ on HRS Si at $30 \mathrm{GHz}$. The return loss can be seen in Fig. 8, where a value of $14.6 \mathrm{~dB}$ was measured at $30 \mathrm{GHz}$ for the antenna on $\mathrm{CMOS} \mathrm{Si}$, which agrees very well with the HFSS simulations. The same antenna on HRS has a stronger resonance at approximately $30.8 \mathrm{GHz}$, but it also has resonances at multiple frequencies due to surface wave modes and parallel plate waveguide modes between the CPW ground plane and the ground plane on the bottom of the wafer. It is seen in Fig. 8 that if the lower ground plane is removed and the wafer placed on quartz, most of the parasitic resonances are removed.
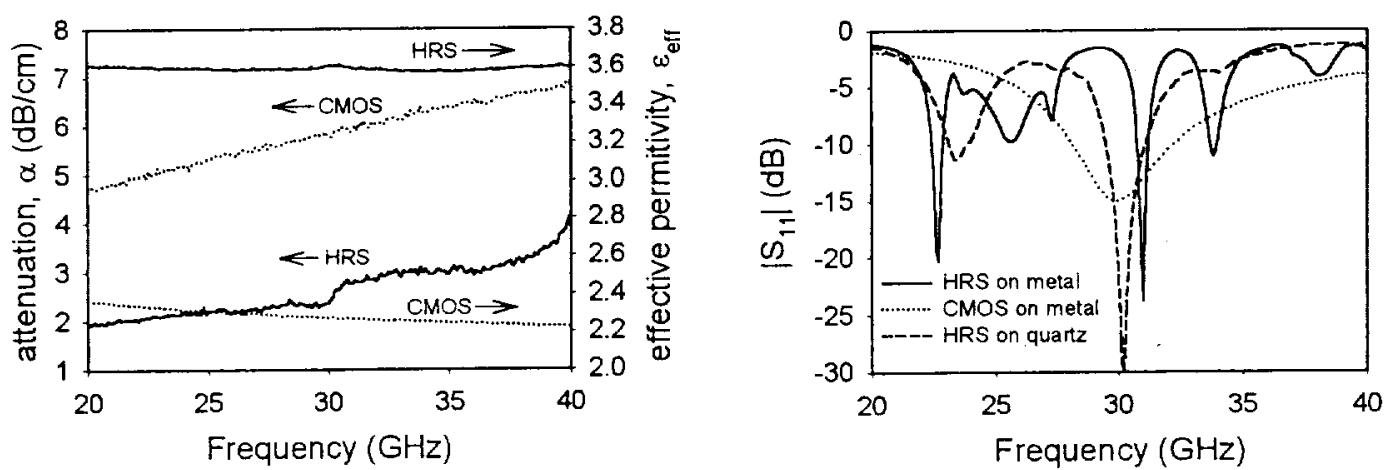

Figure 7: Measured attenuation and effective permittivity of CPW feed lines on CMOS and HRS wafers.

To characterize the radiation properties of the folded-slot antenna, the E- and H-plane patterns were measured at $30 \mathrm{GHz}$ using a novel antenna pattern measurement system. The patterns are measured while the DUT antenna is excited by RF probes and the wafer is sitting on the metal wafer chuck of the RF probe station. The second antenna with the detector is swept in an arc around the DUT antenna. While this system permits quick radiation pattern measurements without dicing the Si wafer, the RF probe does shield the E-plane pattern results, which accounts for the asymmetry and the low power levels for angles less than -20 degrees in Fig. 9. Measurements are shown in Figs. 9 and 10 for the E- and H-planes, respectively. As can be observed in Fig. 9, the folded slot antenna has a main lobe around 0 degrees (broadside), but also radiates power in the 
form of surface waves as witnessed by the strong lobe around 80 degrees. This surface wave mode radiation is higher for the HRS wafer, which agrees with the results discussed with regard to Fig. 8 . HFSS simulations did not reveal this behavior since radiation boundaries are placed on the sidewalls and the ground width was much larger. Figure 10 shows the un-normalized H-plane pattern, which is smooth with a maximum at 0 degrees as is expected. Figure 10 also shows that while folded slot antennas on an HRS wafer have higher surface wave mode problems, the lower line attenuation yields significantly higher gain.

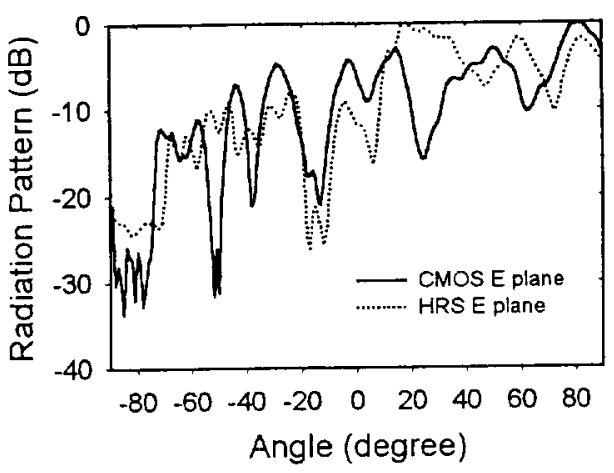

Figure 9: Measured E-plane pattern for folded slot antennas.

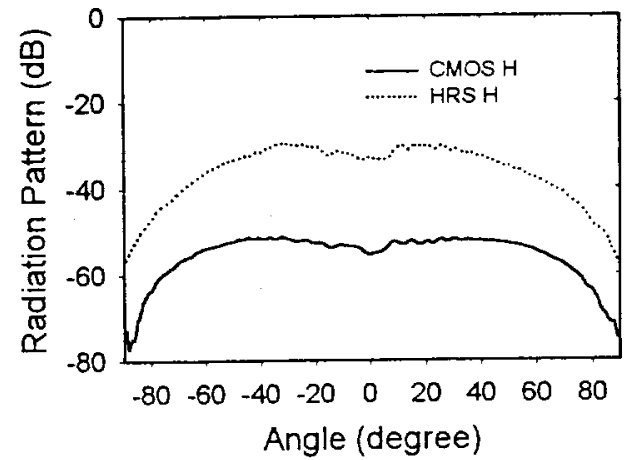

Figure 10: Measured H-plane pattern for folded slot antennas.

\section{CONCLUSIONS}

A CPW folded slot antenna operating at $30 \mathrm{GHz}$ has been characterized for the first time on a low resistivity Si substrate with a polyimide interface layer and compared to the same antenna on an HRS wafer. Experimental results of the antenna on CMOS showed a $30.5 \mathrm{GHz}$ resonance with a $14.6 \mathrm{~dB}$ return loss, an E-plane pattern with a main lobe at broadside and strong surface waves around 80 degrees, as well as a smooth H-plane with a maximum at broadside. These results are in good agreement with HFSS simulations. The same antenna on HRS showed a stronger return loss resonance and higher antenna gain, but stronger surface wave mode issues that may limit its usefulness.

\section{ACKNOWLEDGEMENTS}

This work was supported by the NSF SGER Award No. 0196376, NSF Career Award No. 9989761, and the Yamacraw Foundation.

\section{REFERENCES}

[1] J.F. Luy et al, "Si/SiGe MMICs," IEEE Trans. Microwave Theory and Techniques, Vol. 43, No. 4, pp. 705-714, April 1995.

[2] J.S. Rieh et al, "X- and Ku-band amplifiers based on Si/SiGe HBTs and micromachined lumped components," IEEE Trans. Microwave Theory and Techniques, Vol. 46, No. 4, pp. 685-694, May 1998.

[3] G.E Ponchak and A. Downey, "Characterization of thin film microstrip lines on polyimide," IEEE Trans. Comp., Packaging and Manuf. Technology-Part B, Vol. 21, No. 2, pp.171-176, May 1998.

[4] G.E. Ponchak and L. Katehi, "Measured attenuation of coplanar waveguide on CMOS grade Si substrates with a polyimide interface layer," IEE Electronic Letters, Vol. 34, No. 13, pp. 1327-1329, June 25, 1998.

[5] T. Weller et al, "Single and double folded-slot antennas on semi-infinite substrates, "IEEE Trans. on Antennas and Propagation, vol. 43, no. 12, pp. 1423-1428, Dec. 1995.

[6] G.E. Ponchak, A. Margomenos and L. Katehi, "Low loss CPW on low resistivity Si substrates with a micromachined polyimide interface layer for RFIC interconnects," submitted to IEEE Trans. on Microwave Theory and Techniques.

[7] R.B. Marks and D.F. Williams, Multical v 1.00, NIST, Boulder, CO. 